J Phys Chem A. 2018 August 09; 122(31): 6372-6380. doi:10.1021/acs.jpca.8b05153.

\title{
Structure Based Modulation of Electron Dynamics in meso-(4- Pyridyl)-BODIPYs: A Computational and Synthetic Approach
}

\author{
Daniel J. LaMaster ${ }^{\star}$, Nichole E. M. Kaufman, Adam S. Bruner, M. Graça H. Vicente ${ }^{\star}$ \\ Department of Chemistry, Louisiana State University, Baton Rouge, Louisiana 70803, United \\ States
}

\begin{abstract}
The effects of structural modification on the electronic structure and electron dynamics of cationic meso-(4-pyridyl)-BODIPYs were investigated. A library of 2,6-difunctionalized meso-(4-pyridyl)BODIPYs bearing various electron-withdrawing substituents was designed, and DFT calculations were used to model the redox properties, while TDDFT was used to determine the effects of functionalization on the excited states. Structural modification was able to restructure the lowlying molecular orbitals to effectively inhibit d-PeT. A new meso-(4-pyridyl)-BODIPY bearing 2,6-dichloro groups was synthesized and shown to exhibit enhanced charge recombination fluorescence. The fluorescence enhancement was determined to be the result of functionalization modulating the kinetics of the excited state dynamics.
\end{abstract}

\section{Graphical Abstract}

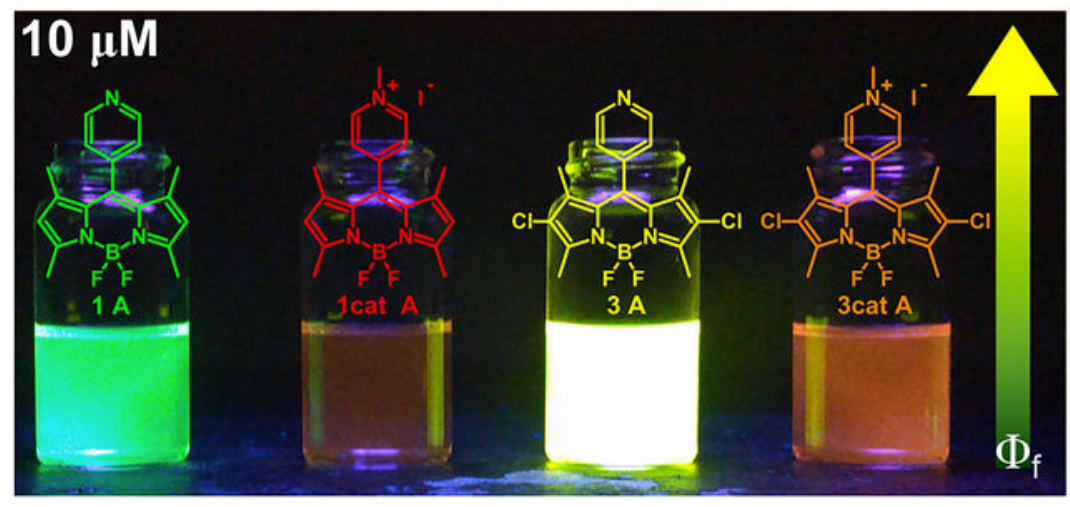

\section{INTRODUCTION}

Over the past 30 years, there has been a considerable amount of research focused on exploring the chemistry, properties, versatility, and applications of BODIPY dyes that range

\footnotetext{
*Corresponding Authors: D J. LaMaster. dlamas1@1su.edu. M. G. H. Vicente. vicente@1su.edu. Supporting Information

The Supporting Information is available free of charge on the ACS Publications website at DOI: 10.1021/acs.jpca.8b05153. Cartesian coordinates for all optimized structures used in calculations, relevant molecular orbital diagrams and TDDFT results, and ${ }^{1} \mathrm{H}$ and ${ }^{13} \mathrm{C}$ NM R for 3A and 3catA (PDF)

The authors declare no competing financial interest.
} 
from tunable laser dyes to probes for biological fluorescence imaging. ${ }^{1-9}$ One aspect that has been underexplored is the development of low molecular weight water-soluble BODIPY derivatives. The first report of a small water-soluble BODIPY was by Wories et al. in 1985, which used sulfonate groups to solubilize the fluorophore, ${ }^{10}$ but by 2007 only a handful of water-soluble BODIPYs had been reported. ${ }^{6}$ Since then, the main strategy used for water solubilization of BODIPY derivatives consists of the introduction of water-solubilizing groups, particularly at the boron center, including polyethylene glycols,,${ }^{9,11-18}$ hydroxyls and ethers, ${ }^{19-21}$ amines, ${ }^{19}$ sulfona-mides, ${ }^{21}$ carboxylates, ${ }^{9,11,17,21-23}$ sulfonates, $,{ }^{9}, 23-30$ phosphonates, ${ }^{9-11}$ quaternary ammonium salts, ${ }^{8,9,24,28,31,32}$ carbohydrates, ${ }^{33-35}$ and peptides. ${ }^{36,37}$ Most of these groups increase the size of the dye, decrease its stability, ${ }^{38,39}$ or utilize negative charges which tend to decrease the cell membrane permeability. However, cationic dyes such as rhodamine ${ }^{7}$ and (poly)cationic porphyrins ${ }^{40}$ are able to electrostatically interact with the negative charges present on cell membranes, increasing their permeability. Therefore, the investigation of small, cationic, and electron-deficient BODIPYs such as meso pyridylBODIPYs is of interest, particularly the 1,3,5,7-

tetramethyl-8-(4-pyridyl)-BODIPY which has $\mathrm{C}_{2}$ symmetry and is readily available from the condensation of 2,4-dimethylpyrrole with 4-pyridylcarboxyaldehyde, followed by oxidation and boron complexation. Previous studies on meso- (4-pyridyl)-BODIPY using transient absorption spectroscopy found that following BODIPY excitation, the dye undergoes donorphotoinduced electron transfer (d-PeT) to a charge-transfer state, which is quenched by subsequent intersystem crossing (ISC), ${ }^{41}$ and the fluorescence quantum yield drops from 0.30 to $<0.001 .^{42}$ Hence, these pyridinium BODIPYs have found applications as nonfluorescent heavy-atom free singlet oxygen generators, and several groups have reported on their ISC enhancement, via bromination and iodination. ${ }^{42-47}$

However, for bioimaging applications, the aforementioned electronic properties of mesopyridinium BODIPYs are undesirable, and no studies have been reported so far on the manipulation of the electronic structure of BODIPYs to restore the fluorescent properties of this type of dye. Herein, we describe the synthetic and computational studies on restoring the fluorescence of meso-pyridinium BODIPYs by inhibiting either the d-PeT process or the ISC. In other BODIPY platforms, there are reports of d-PeT inhibition ${ }^{48-50}$ and reduced photobleaching ${ }^{51}$ (i.e., increased photostability) achieved by installation of electronwithdrawing groups at the 2,6-positions. Using this strategy, a small library of BODIPYs bearing various electron-withdrawing groups at the 2,6-positions was designed (shown in Figure 1) and a combination of density functional theory (DFT) and time-dependent DFT (TDDFT) calculations were used to determine whether this reported methodology applies to the meso-pyridinium BODIPY dyes.

\section{COMPUTATIONAL METHODS}

All calculations were performed using the NWChem 6.5 software package. ${ }^{52}$ Molecular properties were calculated for gas phase structures at $0 \mathrm{~K}$. The ground state structures were optimized using density functional theory with the hybrid B3LYP ${ }^{53,54}$ functional, the $6-31+G^{* *}$ basis set, and confirmed by subsequent frequency calculations. The energies of the HOMO were then used to calculate the vertical ionization potentials (VIPs) as a means of evaluating the electron deficiency of the BODIPY, which influences the d-PeT to the 
pyridinium ring. Furthermore, these VIPs can be used to then calculate the experimental oxidation potentials as shown by Zhan and co-workers. ${ }^{55}$ Electronic transitions were calculated for each optimized structure using TDDFT with the B3LYP and the rangeseparated CAM-B3LYP ${ }^{56}$ functionals. Here, the range-separated functional is used to describe the long-range interactions necessary to capture transitions between the BODIPY and the pyridinium ring. To evaluate the effect of functionalization on the quenching of the charge-transfer state, structures were optimized on their first singlet excited state $\left(\mathrm{S}_{1}\right)$. This yields the singlet-triplet energy gap involved in the intersystem crossing.

\section{EXPERIMENTAL METHODS}

\section{Materials.}

All solvents and reagents were obtained from Sigma-Aldrich, Tokyo Chemical Industry, and Honeywell International Incorporated. The solvents were dried over $4 \AA$ molecular sieves as needed. The reagents were used as received without purification.

\section{Synthesis and Characterization.}

Reactions were monitored using $0.2 \mathrm{~mm}$ silica gel plates (with indicator, polyester backed, $60 \AA$, precoated) and UV lamp. Liquid chromatography was performed on preparative TLC plates or via silica gel column chromatography $(60,230-400$ mesh) and all solvent systems were buffered with $0.1 \%$ triethylamine. NM R spectra were obtained on $400\left({ }^{1} \mathrm{H}\right)$ and 500 $\mathrm{MHz}\left({ }^{13} \mathrm{C}\right)$ spectrometers at room temperature. Chemical shifts $(\delta)$ are given in parts per million (ppm) in $\mathrm{CDCl}_{3}$ (7.27 ppm for ${ }^{1} \mathrm{H}$ NMR, $77.0 \mathrm{ppm}$ for ${ }^{13} \mathrm{C} \mathrm{NMR}$ ) or $\mathrm{C}_{2} \mathrm{D}_{6} \mathrm{SO}$ (2.50 ppm for ${ }^{1} \mathrm{H}$ NMR, $39.5 \mathrm{ppm}$ for $\left.{ }^{13} \mathrm{CNM} \mathrm{R}\right)$; coupling constants $(J)$ are given in hertz. Highresolution mass spectra were measured on an ESI-TOF mass spectrometer in positive mode. All absorption spectra were recorded on a Varian Cary 50 Bio and emission spectra were recorded on a PerkinElmer LS 55 Luminescence Spectrophotometer, at room temperature. Spectrophotometric grade solvents and quartz cuvettes (10 mm path length) were used. For the determination of the optical density ( $\varepsilon$ ), solutions with absorbance at $\lambda_{\max }$ between 0.5 and 1 were used. For the determination of quantum yields, dilute solutions with absorbance between 0.03 and 0.05 at the particular excitation wavelength $(462,473,488,496 \mathrm{~nm}$ for 1A, IcatA, 3A, and 3catA, respectively) were used, and all measurements were taken within $8 \mathrm{~h}$ after solution preparation. ${ }^{57,58}$ The external standards employed were rhodamine $6 \mathrm{G}$ in methanol and water and $\mathrm{Ru}(\mathrm{bpy})_{3} \mathrm{Cl}_{2}$ in water. BODIPY $\mathbf{1 A}$ was prepared following a reported procedure ${ }^{59}$ with a modified purification using 1:4 EtOAc/dichloromethane and 4\% EtOAc/dichloromethane instead of 1:1 EtOAc/hexanes due to the increased solubility. BODIPY 1catA was prepared in the same way as 3catA and its physical data matched literature reports. ${ }^{41}$

2,6-Dichloro-8-(4-pyridyl)-I,3,5,7-tetramethyl-BODIPY(3A).-To an oven-dried flask charged with BODIPY $1 \mathrm{~A}(0.0118 \mathrm{~g}, 0.04 \mathrm{mmol})$ in dichloromethane $(10.0 \mathrm{~mL})$ was dropwise added trichloroisocyanuric acid $(0.0076 \mathrm{~g}, 0.03 \mathrm{mmol}, 2.62$ equiv) in dichloromethane $(4.0 \mathrm{~mL})$, and the mixture was stirred at room temperature under a nitrogen atmosphere. After TLC showed consumption of the starting material (about $30 \mathrm{~min}$ ), the solution was purified over silica by column chromatography eluting with $2 \%$ methanol/ 
dichloromethane, yielding $10 \mathrm{mg}, 69 \%$ yield (red solid). ${ }^{1} \mathrm{H} \mathrm{NMR}\left(400 \mathrm{MHz}, \mathrm{CDCl}_{3}\right): \delta=$ 8.85-8.84 (dd, $J=5.9$ and $1.5 \mathrm{~Hz}, 2 \mathrm{H}), 7.31-7.30(\mathrm{dd}, J=5.9$ and $1.6 \mathrm{~Hz}, 2 \mathrm{H}), 2.61(6 \mathrm{H}, \mathrm{s})$, $1.42(6 \mathrm{H}, \mathrm{s}) \mathrm{ppm} .{ }^{13} \mathrm{C} \mathrm{NMR}\left(500 \mathrm{MHz}, \mathrm{CDCl}_{3}\right) \delta=153.7,150.9,142.8,138.2,137.5,128.6$, 123.3, 123.1, 12.5, $12.2 \mathrm{ppm}$. HRMS (ESI): $\mathrm{m} / z$ calcd (\%) for $\mathrm{C}_{18} \mathrm{H}_{19} \mathrm{BF}_{2} \mathrm{~N}_{3} \mathrm{Cl}_{2}, 393.0891$ $[\mathrm{M}+\mathrm{H}]^{+}$; found, 393.0902. UV/vis:( $\left.\mathrm{CH}_{3} \mathrm{CN}\right) \lambda_{\max }=518, \lambda_{\mathrm{em}}=546 \mathrm{~nm} ;\left(\mathrm{CH}_{2} \mathrm{Cl}_{2}\right): \lambda_{\max }$ $=534, \lambda_{\mathrm{em}}=563 \mathrm{~nm}$.

\section{2,6-Dichloro-8-(N-methyl-4-pyridyl)-1,3,5,7-tetramethyl-BODIPY (3catA).-In a} $10 \mathrm{~mL}$ round-bottom flask wrapped in foil, BODIPY $3 \mathrm{~A}(0.0111 \mathrm{~g}, 0.028 \mathrm{mmol})$ was dissolved in anhydrous $\mathrm{MeCN}(2.0 \mathrm{~mL})$ and methyl iodide $(2.0 \mathrm{~mL})$. After refluxing for $1 \mathrm{~h}$, TLC showed consumption of starting material and the solvent was removed under reduced pressure. Yield: $15 \mathrm{mg}, 100 \%$ (greenish-gray solid). ${ }^{1} \mathrm{H}$ NMR (400 MHz, DMSO- $d_{6}$ ): $\delta=$ 9.24-9.23 (d, $J=6.6 \mathrm{~Hz}, 2 \mathrm{H}), 8.44-8.42(\mathrm{~d}, J=6.7 \mathrm{~Hz}, 2 \mathrm{H}), 4.47(3 \mathrm{H}, \mathrm{s}), 2.55(6 \mathrm{H}, \mathrm{s}), 1.30$ $(6 \mathrm{H}, \mathrm{s}) \mathrm{ppm} .{ }^{13} \mathrm{C}$ NMR (500 MHz, DMSO- $\left.d_{6}\right): \delta=154.0,149.6,147.5,138.0,136.7,128.2$, 128.1, 123.0, 49.0, 13.2, 12.9 ppm. HRMS (ESI): $\mathrm{m} / z$ calcd (\%) for $\mathrm{C}_{19} \mathrm{H}_{19} \mathrm{BF}_{2} \mathrm{~N}_{3} \mathrm{Cl}_{2}$, 407.1048 [M*] ${ }^{+}$; found, 407.1048. UV/vis: $\left(\mathrm{CH}_{3} \mathrm{CN}\right) \lambda_{\max }=530, \lambda_{\mathrm{em}}=596 \mathrm{~nm} ;\left(\mathrm{CH}_{2} \mathrm{Cl}_{2}\right)$ $\lambda_{\max }=548, \lambda_{\mathrm{em}}=570,645 \mathrm{~nm}$.

\section{RESULTS AND DISCUSSION}

\section{Quantum Chemical Calculations.}

When orbital energy levels are evaluated, molecular orbitals are calculated for the whole system to illustrate which parts of the molecule are involved in electronic transitions (e.g., BODIPY core or pyridinium ring). This shows how functionalization affects transitions without the need to partition the molecule into fragments, which can introduce artifacts into the calculations. ${ }^{49,60-62}$ It is worth noting that these calculations do not take into account spin-orbit coupling. Derivatives $\mathbf{4 A}$ and $\mathbf{5 A}$ both include large halogens known to induce the heavy-atom effect of quenching their fluorescence. ${ }^{45}$ They are included in this study for the difference in the halogens' electronegativities, which will alter the vertical ionization potentials and add additional data points for potential results. In discussing the LUMOs of the cationic derivatives, the LUMOs localized on the pyridinium and BODIPY cores are denoted as $\mathrm{LUMO}_{\mathrm{Py}}$ and $\mathrm{LUMO}_{\mathrm{BDP}}$, respectively.

\section{Calculated Oxidation Potentials.}

The vertical ionization potentials used to calculate the oxidation potentials for the neutral library are shown in Table 1. Here, the VIPs increase as the BODIPYs become more electron deficient. In addition, the $\Delta$ VIPs are also shown, given by the difference between the VIP of a given molecule and that of $1 \mathrm{~A}$. The $\Delta$ VIPs show how the VIP changes with the functionalization. For the halogenated systems $\mathbf{3 A - 5 A}$, the VIPs decreased for lower halogen electronegativity, as expected. The difluoro derivative (2A), however, gave the smallest VIP increase, which can be explained by looking at the molecular orbital compositions. Fluorine is quite small, having high electronegativity and relatively stable valence electrons (i.e., low energy). In $\mathbf{2 A}$, the highest energy orbital involving the fluorine atoms is the HOMO-7, which is $3.281 \mathrm{eV}$ lower in energy than the HOMO. The chlorines in 3A contribute to the HOMO-1 while the halogens in $\mathbf{4 A}$ and $\mathbf{5 A}$ contribute to the HOMO. 
Since 3A-5A halogens contribute to orbitals near the HOMO, they have a larger influence on respective VIPs.

The carbonyl derivatives are also included in Table 1. Unlike the halogenated systems, this group of carbonyl derivatives $(\mathbf{6 A - 1 0 A})$ does not show a direct correlation to the strength of the withdrawing group. Instead, the VIP depends more on how electrons contribute to higher energy orbitals. Since several electrons are involved in these functional groups, VIP values can be close in energy. As such, $\Delta$ VIPs are also calculated to better capture the energy differences (Table 1). For the carbonyl systems, the chloroformyl (7A) had the largest increase, followed by diamide (9A), dialdehyde (8A), diester (10A), and monoaldehyde (6A). If these had been ranked by decreasing electron-withdrawing strength, the expected order would be 10A, 9A, 8A, 7A, and 6A. The large increase in the chloroformyl (7A) is best explained by the contributions of the chlorine to the HOMO, which shifts the VIP by $+0.416 \mathrm{eV}$ relative to $\mathbf{6 A}$ monoaldehyde. The other outlier $\mathbf{1 0 A}$ (diester) has no contributions to the HOMO, HOMO -1, or HOMO -2 orbitals, each of which had significant contributions from other withdrawing groups. Since the ester groups do not participate in the high-energy orbitals of the valence, they have a small impact on the VIP. Continuing with the remaining derivatives (11A and 12A), the values increased consistent with electronwithdrawing strength. This trend is expected with the dicyano derivative (12A) giving the largest overall increase of $1.218 \mathrm{eV}$.

\section{Time-Dependent DFT Calculations.}

The first two excitations from the TDDFT results for the neutral library are summarized in the Supporting Information Table S1. These results show the HOMO $\rightarrow$ LUMO transition to be the first excitation with a strong oscillator strength $(f)$ for all 12 dyes. The second excitation was HOMO-1 to LUMO, with a few exceptions.

The TDDFT analysis of the first cationic derivatives (Supporting Information Table S2) revealed that the B3LYP hybrid functional is insufficient to accurately describe their excited states. DFT is known to fail for charge transfer in molecules and range-separated functionals have been developed to address this. ${ }^{56}$ The typical BODIPY is known to have a strong $\mathrm{S}_{0} \rightarrow$ $\mathrm{S}_{1}$ transition and adding the pyridinium with a low-lying LUMO should introduce a single electronic transition lower in energy than the HOMO $\rightarrow$ LUMO transition of the BODIPY. 63-65 The failure can be seen in the degeneracy of both the $\mathrm{LUMO}_{\mathrm{BDP}}$ and $\mathrm{LUMO}_{\mathrm{Py}+1}$ as well as the extra transitions from sub-HOMO orbitals that appeared between the HOMO $\rightarrow$ LUMO and HOMO $\rightarrow$ LUMO+1 transitions. In these cases, the first (lowest energy) transition was HOMO $\rightarrow$ LUMO where the LUMO is localized on the pyridinium ring. Although the second transition should have corresponded to the BODIPY core excitation $(\mathrm{HOMO} \rightarrow \mathrm{LUMO}+1)$, it was calculated to be much higher in energy as the fifth transition. Collectively, this indicated the B3LYP functional was not sufficient to describe the longrange interactions, prompting the use of a range-separated functional (CAM-B3LYP) ${ }^{65}$ Using the TDDFT and the CAM-B3LYP functional, the vertical excitation energy (VEE), oscillator strength $(f)$, and predominant transition character (e.g., mostly $\mathrm{H} \rightarrow \mathrm{L}$ ) were determined for the first two transitions. These results are summarized in Table 2 and are consistent with experimental results for these fluorophores. ${ }^{42,65,66}$ 
Figure $\mathrm{S} 1$ of the Supporting Information shows the HOMO, LUMO, and LUMO+1 orbitals, localized on the BODIPY, pyridinium, and BODIPY, respectively, for all cationic 12 dyes. The first transition was found to be a strictly $\mathrm{HOMO} \rightarrow \mathrm{LUMO}_{\mathrm{Py}}$ dark state, while the second transition was $\mathrm{HOMO} \rightarrow \mathrm{LUMO}_{\mathrm{BDP}}$ with a strong oscillator strength. These results indicate that the BODIPYs' strong absorption will decay to the charge-transfer state. As such, it can be concluded that the BODIPY core oxidation potential has a negligible impact on the d-PeT charge-transfer state for this BODIPY platform.

To interpret these results, consider both the molecular orbitals of the BODIPY core and the excited state potential energy surface. For the BODIPY systems, the HOMO is partially localized on the 2,6-positions; thus, functionalizing these positions with electronwithdrawing groups decreases the energy of the HOMO. With the BODIPY and pyridinium orbitals orthogonal to each other, changes to the BODIPY core orbitals due to functionalization do not significantly affect the orbitals on the pyridinium, which explains

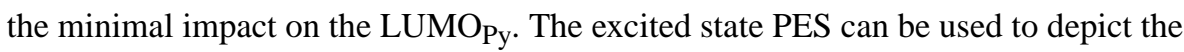
BODIPY as a donor-acceptor system and interpret how the states should be ordered to prevent formation of a long-lived charge-transfer state. After excitation to the $\mathrm{S}_{2}$ $\left(\mathrm{LUMO}_{\mathrm{BDP}}\right)$, the system will nonradiatively decay to the LUMO (i.e., $\mathrm{LUMO}_{\mathrm{Py}}$ ) forming the charge-transfer state that quenches the fluorescence. From this, the excitation itself can be viewed as the donation, so the only way to inhibit the d-PeT is to either raise the energy of the undesired acceptor $\left(\mathrm{LUMO}_{\mathrm{Py}}\right.$ ) or, alternatively, lower the energy of the desired acceptor $\left(\mathrm{LUMO}_{\mathrm{BDP}}\right)$.

Since it is of interest to raise the energy of the $\mathrm{LUMO}_{\mathrm{Py}}$, methoxy groups were used to donate electron density into the ring. Although dimethylamino groups are better electron donors, their basic nature and large size would have sterically hindered the pyridine methylation during synthesis. To evaluate the best positions for the methoxy groups, the orbitals of the $N$-methylpyridinium cation (without the BODIPY) were calculated to determine where the LUMO is localized using DFT and the CAM-B3LYP functional. From this, the LUMOPy is located primarily on the 3,5-and 2,6-positions shown in Figure S2 in the Supporting Information, and the latter was chosen for synthetic practicality. Proof of concept was obtained from a small test case by modeling the $N$-methylpyridinium (N-MePy ${ }^{+}$, A), 2-methoxy- $N$-methylpyridinium (2-OMe-N-MePy ${ }^{+}, \mathbf{B}$ ), and 2,6-dimethoxy- $N$ methylpyridinium (2,6-DiOMe-N-MePy $\left.{ }^{+}, \mathbf{C}\right)$ cations (Supporting Information, Table S3). It was found that one methoxy group could increase the LUMO energy by $0.509 \mathrm{eV}$ and a second could raise it further by an additional $0.488 \mathrm{eV}$ with an overall increase of $1.003 \mathrm{eV}$.

In addition to raising the energy of the $\mathrm{LUMO}_{\mathrm{Py}}$ to reorder the states, we can also consider lowering the energy of $\mathrm{LUMO}_{\mathrm{BDP}}$. The $\mathrm{LUMO}_{\mathrm{BDP}}$ is largely localized on the meso-position and to a smaller extent on the 1,7-positions. Since the2,6-dicyano-BODIPY (12) had the largest oxidation potential increase, it has the greatest shift in the orbital energy. Thus, the1.7-dicyanoBODIPY (13A) was chosen to model the effects of lowering the LUMO ${ }_{\text {BDP. }}$ The new additions to the original library and their calculated VIPs are shown in Figure 2 and Table 3, respectively. The orbital energies of BODIPYs 1 catA-C, 12catA-C, and 13catA-C (collectively referenced as Py'-BODIPYs) are shown in Table 4 while the TDDFT results and MO plots are summarized in the Supporting Information Figure S3 and 
Table S4, respectively. Moving the cyano groups from HOMO (12catA) to LUMO (13catA) structural positions decreased the VIP by $0.227 \mathrm{eV}$ but was able to effectively reorder the $\mathrm{LUMO}_{\mathrm{Py}}$ and $\mathrm{LUMO}_{\mathrm{BDP}}$, providing a $0.273 \mathrm{eV}$ energy gap.

The addition of methoxy groups to the pyridine unit slightly decreased the overall oxidation potential of the dyes by $0.025 \mathrm{eV}$ per OMe. It should be noted that for series $12 \mathrm{~A}-\mathrm{C}$, each OMe group decreased the VIP by $\sim 0.03 \mathrm{eV}$. However, for series 13A-C, there was an additive effect where the first OMe caused a $0.057 \mathrm{eV}$ decrease while the second caused an additional $0.191 \mathrm{eV}$ decrease.

Alteration of the $\mathrm{LUMO}_{\mathrm{Py}}$ alone was shown to be an ineffective strategy by the lack of change in the orbitals of 1catA-C. The combination of the most effective LUMO $_{\mathrm{Py}}$ increase and BODIPY VIP increase functionalizations (12catC) was able to raise the $\mathrm{LUMO}_{\mathrm{Py}}$ energy above that of the $\mathrm{LUMO}_{\mathrm{BDP}}$, though the energy difference is rather small at $0.080 \mathrm{eV}$. As such, $\mathrm{d}-\mathrm{PeT}$ is still possible due to vibrational excitation. Adjusting the $\mathrm{LUMO}_{\mathrm{BDP}}(\mathbf{B}$ catA $-\mathbf{C})$, however, effectively reordered the orbitals and separated them by energy differences of $0.273,0.793$, and $1.115 \mathrm{eV}$, respectively, which prevents d-PeT from occurring. The TDDFT calculations also indicate this with the first transition being HOMO

$\rightarrow$ LUMO for 12catC and 13catA-C and corresponding to the typical BODIPY excitation.

\section{Intersystem Crossing (ISC).}

Since most of the BODIPYs studied will still undergo d-PeT, the effects of 2,6difunctionalization on ISC are of interest. To this end, 1catA and 12catA were studied further. Both structures were optimized along their $S_{1}$ excited states using CAM-B3LYP after which the energies of the $S_{1}$ and the triplet excitation with the same transition character ( $T_{2}$ for both dyes) were compared. The results, summarized in Table 5, show that the nature of the transitions, the orbital populations, the states involved, and the singlet-triplet energy gaps are identical for both dyes. These results indicate that the electronic possibility of ISC is unchanged in the 2,6-difunctionalized derivatives.

\section{Synthesis and Spectroscopic Properties.}

BODIPYs 1A and 1catA were synthesized using the previously reported methodology. ${ }^{59} \mathrm{In}$ summary, 2,4-dimethylpyrrole reacted with 4-pyridylcarboxaldehyde in the presence of TFA to afford the dipyrromethane, which after DDQ oxidation and $\mathrm{BF}_{3}$ complexation produced BODIPY 1A in 46\% yield. Chlorination of 1A using trichloroisocyanuric acid in dichloromethane at room temperature, gave BODIPY 3A in 68\% yield. The cationic BODIPYs 1catA and 3catA were obtained by methylation using methyl iodide in acetonitrile, as previously reported. ${ }^{44}$

The absorption and emission spectra of BODIPYs 1A, 1Acat, 3A, and 3Acat were obtained at room temperature in acetonitrile while the spectra for 1catA and 3catA were also measured in water (Table 6 and Figure 3). The absorption spectra displayed the characteristic BODIPY profile with a sharp peak due to the $S_{0} \rightarrow S_{1}\left(\pi \rightarrow \pi^{*}\right)$ transition with a higher energy shoulder corresponding to the first vibrational mode. The absorption and emission spectra of 1catA and 3catA did not change upon switching the solvent from 
acetonitrile to water. In both cases, methylation caused about $10 \mathrm{~nm}$ bathochromic shift in the absorption while the emission shifted substantially to about $600 \mathrm{~nm}$ in both acetonitrile and water, and exhibited a broad, poorly resolved profile characteristic of luminescent charge recombination. These results are in agreement with previous observations of the spectroscopic behavior of $1 \mathrm{~A}$ and $1 \mathrm{cat} \mathrm{A}$ in dichloromethane. ${ }^{41,44}$ With the chlorines on the 2,6-positions being mildly electron-withdrawing groups, they had a small to moderate impact on the fluorescence quantum yield of both the neutral and ionic derivatives in acetonitrile, resulting in a 2-fold increase for $\mathbf{3 A}$ and about a 2.5 -fold increase for 3 catA. The quantum yield has been previously observed to increase upon 2,6-dichlorination of meso-arylBODIPYs., ${ }^{2,67,69}$ After accounting for the 2-fold increase in $\Phi_{\mathrm{f}}$ from $\mathbf{1 A}$ to $\mathbf{3 A}$, 3catA had an additional $26 \%$ increase from 1catA. The fluorescence quantum yields decreased upon switching from acetonitrile to water due to the increased solvemt polarity stabilizing the charge-transfer state which facilitated the subsequent deactivation by ISC; however, this resulted in an order of magnitude increse from 1catA to 3catA.

With the d-PeT acceptor orbitals being unaffected by the functionalization, the fluorescence enhancement observed for 3catA in acetonitrile is attributed to an alteration of the excited state lifetime. This is the result of the increased oxidation potential increasing the rate of charge recombination by enhancing the electron-hole electrostatic interaction. Recalling the calculated VIPs, the dichlorination only resulted in a $0.339 \mathrm{eV}$ increase while installation of the 2,6-dicyano groups resulted in a $1.218 \mathrm{eV}$ increase. This suggests that $12 \mathrm{~A}$ should display photophysical properties with a dramatic improvement over $\mathbf{3 A}$. The synthesis of such a derivative is currently underway in our laboratories.

\section{CONCLUSIONS}

Several electronic structure-based molecular properties for a library of meso-(4-pyridyl) BODIPYs have been calculated and shown that the combination of increasing the BODIPY core oxidation potential as well as increasing the pyridinium reduction potential, can reorder the low-lying excited states which inhibits d-PeT; however, decreasing the BODIPY core reduction potential has a greater capacity for both reordering those states and sufficiently separating them. The states involved in the ISC were found to be unaffected by the 2,6functionalization with various electron-withdrawing groups. Additionally, a new fluorescent meso-(4-pyridium)-BODIPY was synthesized, and a novel mechanism of fluorescence enhancement was demonstrated. In our work, structure based modulation of excited state electron dynamics was demonstrated and manipulation of fluorescence behavior was observed.

\section{Supplementary Material}

Refer to Web version on PubMed Central for supplementary material.

\section{ACKNOWLEDGMENTS}

This work was supported by the National Science Foundation (CHE 1800126) and the National Institutes of Health (R25 GM069743). The authors are thankful to the Louisiana State University High Performance Computing Center (http://www.hpc.lsu.edu) for use of its computational resources in conducting this research. 


\section{REFERENCES}

(1). Bañuelos J BODIPY Dye, the Most Versatile Fluorophore Ever? Chem. Rec 2016, 16, 335-348. [PubMed: 26751982]

(2). Duran-Sampedro G; Agarrabeitia AR; Garcia-Moreno I; Costela A; Bañuelos J; Arbeloa T; López AI; Chiara JL; Ortiz MJ Chlorinated BODIPYs: Surprisingly Efficient and Highly Photostable Laser Dyes. Eur. J. Org. Chem 2012, 2012, 6335-6350.

(3). Ulrich G; Ziessel R; Harriman A The Chemistry of Fluorescent BODIPY Dyes: Versatility Unsurpassed. Angew. Chem., Int. Ed 2008, 47, 1184-1201.

(4). Hou J-T; Ren WX; Li K; Seo J; Sharma A; Yu X-Q; Kim JS Fluorescent Bioimaging of pH: From Design to Applications. Chem. Soc. Rev 2017, 46, 2076-2090. [PubMed: 28317979]

(5). Terai T; Nagano T Small-Molecule Fluorophores and Fluorescent Probes for Bioimaging. Pfluegers Arch 2013, 465, 347-359. [PubMed: 23412659]

(6). Loudet A; Burgess K BODIPY Dyes and Their Derivatives: Syntheses and Spectroscopic Properties. Chem. Rev 2007, 107, 4891-4932. [PubMed: 17924696]

(7). Kowada T; Maeda H; Kikuchi K BODIPY-Based Probes for the Fluorescence Imaging of Biomolecules in Living Cells. Chem. Soc. Rev 2015, 44, 4953-4972. [PubMed: 25801415]

(8). Zhu H; Fan J; Mu H; Zhu T; Zhang Z; Du J; Peng X DPet-Controlled “Off-on” Polarity-Sensitive Probes for Reporting Local Hydrophilicity within Lysosomes. Sci. Rep 2016, 6, 35627. [PubMed: 27767190]

(9). Fan G; Yang L; Chen Z Water-Soluble BODIPY and Aza-BODIPY Dyes: Synthetic Progress and Applications. Front. Chem. Sci. Eng 2014, 8, 405-417.

(10). Wories HJ; Koek JH; Lodder G; Lugtenburg J; Fokkens R; Driessen O; Mohn GR A Novel Water-Soluble Fluorescent Probe: Synthesis, Luminescence and Biological Properties of the Sodium Salt of the 4-Sulfonato-3,3' $, 5,5^{\prime}$-Tetramethyl-2,2' -Pyrromethen-1,1' -BF2 Complex. Red. Trav. Chim. Pays-Bas 1985, 104, 288-291.

(11). Bura T; Ziessel R Water-Soluble Phosphonate-Substituted BODIPY Derivatives with Tunable Emission Channels. Org. Lett 2011, 13, 3072-3075. [PubMed: 21598985]

(12). Zhu S; Zhang J; Vegesna G; Luo F-T; Green SA; Liu H Highly Water-Soluble Neutral BODIPY Dyes with Controllable Fluorescence Quantum Yields. Org. Lett 2011, 13, 438-441. [PubMed: 21175151]

(13). Zhu S; Dorth N; Zhang J; Vegesna G; Li H; Luo F-T; Tiwari A; Liu H Highly Water-Soluble Neutral near-Infrared Emissive BODIPY Polymeric Dyes. J. Mater. Chem 2012, 22, 2781-2790.

(14). Zhu S; Zhang J; Janjanam J; Vegesna G; Luo F-T; Tiwari A; Liu H Highly Water-Soluble BODIPY-Based Fluorescent Probes for Sensitive Fluorescent Sensing of Zinc(II). J. Mater. Chem. B 2013, 1, 1722-1728.

(15). Zhu Y; Lin W; Zhang W; Feng Y; Wu Z; Chen L; Xie Z Pegylated BODIPY Assembling Fluorescent Nanoparticles for Photo-dynamic Therapy. Chin. Chem. Lett 2017, 28, 1875-1877.

(16). Vegesna GK; Sripathi SR; Zhang J; Zhu S; He W; Luo F-T; Jahng WJ; Frost M; Liu H Highly Water-Soluble BODIPY-Based Fluorescent Probe for Sensitive and Selective Detection of Nitric Oxide in Living Cells. ACS Appl Mater. Interfaces 2013, 5, 4107-4112. [PubMed: 23614822]

(17). Li X; Gao X; Shi W; Ma H Design Strategies for Water-Soluble Small Molecular Chromogenic and Fluorogenic Probes. Chem. Rev 2014, 114, 590-659. [PubMed: 24024656]

(18). Brizet B; Bernhard C; Volkova Y; Rousselin Y; Harvey PD; Goze C; Denat F Boron Functionalization of BODIPY by Various Alcohols and Phenols. Org. Biomol Chem 2013, 11, 7729-7737. [PubMed: 24113836]

(19). Courtis AM; Santos SA; Guan Y; Hendricks JA; Ghosh B; Szantai-Kis DM; Reis SA; Shah JV; Mazitschek R Monoalkoxy BODIPYs-a Fluorophore Class for Bioimaging. Bioconjugate Chem 2014, 25, 1043-1051.

(20). Nguyen AL; Bobadova-Parvanova P; Hopfinger M; Fronczek FR; Smith KM; Vicente MGH Synthesis and Reactivity of 4,4-Dialkoxy-BODIPYs: An Experimental and Computational Study. Inorg. Chem 2015, 54, 3228-3236. [PubMed: 25797597] 
(21). Takeda A; Komatsu T; Nomura H; Naka M; Matsuki N; Ikegaya Y; Terai T; Ueno T; Hanaoka K; Nagano T; et al. Unexpected Photo-Instability of 2,6-Sulfonamide-Substituted BODIPYs and Its Application to Caged Gaba. ChemBioChem 2016, 17, 1233-1240. [PubMed: 27038199]

(22). Komatsu T; Urano Y; Fujikawa Y; Kobayashi T; Kojima H; Terai T; Hanaoka K; Nagano T Development of 2,6-Carboxy-Substituted Boron Dipyrromethene (BODIPY) as a Novel Scaffold of Ratiometric Fluorescent Probes for Live Cell Imaging. Chem. Commun 2009, 45, 7015-7017.

(23). Dilek Ö; Bane SL Synthesis, Spectroscopic Properties and Protein Labeling of Water Soluble 3,5Disubstituted Boron Dipyrromethenes. Bioorg. Med. Chem. Lett 2009, 19, 6911-6913. [PubMed: 19879138]

(24). Niu S-L; Ulrich G; Ziessel R; Kiss A; Renard P-Y; Romieu A Water-Soluble BODIPY Derivatives. Org. Lett 2009, 11, 2049-2052. [PubMed: 19379006]

(25). Li L; Han J; Nguyen B; Burgess K Syntheses and Spectral Properties of Functionalized, WaterSoluble BODIPY Derivatives. J. Org. Chem 2008, 73, 1963-1970. [PubMed: 18271598]

(26). Yao H-W; Zhu X-Y; Guo X-F; Wang H An Amphiphilic Fluorescent Probe Designed for Extracellular Visualization of Nitric Oxide Released from Living Cells. Anal. Chem 2016, 88, 9014-9021. [PubMed: 27545350]

(27). Kim J; Kim Y A Water-Soluble Sulfonate-BODIPY Based Fluorescent Probe for Selective Detection of $\mathrm{HOCl} / \mathrm{OCl}$ - in Aqueous Media. Analyst 2014, 139, 2986-2989. [PubMed: 24816680]

(28). Niu S-L; Massif C; Ulrich G; Ziessel R; Renard P-Y; Romieu A Water-Solubilisation and BioConjugation of a Red-Emitting BODIPY Marker. Org. Biomol. Chem 2011, 9, 66-69. [PubMed: 21088764]

(29). Marfin YS; Aleksakhina EL; Merkushev DA; Rumyantsev EV; Tomilova IK Interaction of BODIPY Dyes with the Blood Plasma Proteins. J. Fluoresc 2016, 26, 255-261. [PubMed: 26520852]

(30). Wu L; Loudet A; Barhoumi R; Burghardt RC.; Burgess K. Fluorescent Cassettes for Monitoring Three-Component Interactions in Vitro and in Living Cells. J. Am. Chem. Soc 2009, 131, 91569157. [PubMed: 19566090]

(31). Niu SL; Massif C; Ulrich G; Renard PY; Romieu A; Ziessel R Water-Soluble Red-Emitting Distyryl-Borondipyrromethene (BODIPY) Dyes for Biolabeling. Chem. - Eur. J 2012, 18, 7229 7242. [PubMed: 22544430]

(32). Niu SL; Ulrich G; Retailleau P; Harrowfield J; Ziessel R New Insights into the Solubilization of BODIPY Dyes. Tetrahedron Lett 2009, 50, 3840-3844.

(33). Nguyen AL; Griffin KE; Zhou Z; Fronczek FR; Smith KM; Vicente MGH Syntheses of 1,2,3Triazole-BODIPYs Bearing up to Three Carbohydrate Units. New J. Chem 2018, 42, 8241-8246.

(34). Lu Z; Mei L; Zhang X; Wang Y; Zhao Y; Li C Water-Soluble BODIPY-Conjugated Glycopolymers as Fluorescent Probes for Live Cell Imaging. Polym. Chem 2013, 4, 5743-5750.

(35). Isaad J; El Achari A A Water Soluble Fluorescent BODIPY Dye with Azathia-Crown Ether Functionality for Mercury Chemo-sensing in Environmental Media. Analyst 2013, 138, 38093819. [PubMed: 23702799]

(36). Zhao N; Williams TM; Zhou Z; Fronczek FR; Sibrian-Vazquez M; Jois SD; Vicente MGH Synthesis of BODIPY-Peptide Conjugates for Fluorescence Labeling of EGFR Over-expressing Cells. Bioconjugate Chem 2017, 28, 1566-1579.

(37). Banappagari S; McCall A; Fontenot K; Vicente MGH; Gujar A; Satyanarayanajois S Design, Synthesis and Characterization of Peptidomimetic Conjugate of BODIPY Targeting HER2 Protein Extracellular Domain. Eur. J. Med. Chem 2013, 65, 60-69. [PubMed: 23688700]

(38). Lincoln R; Greene LE; Krumova K; Ding Z; Cosa G Electronic Excited State Redox Properties for BODIPY Dyes Predicted from Hammett Constants: Estimating the Driving Force of Photoinduced Electron Transfer. J. Phys. Chem. A 2014, 118, 10622-10630. [PubMed: 25066755]

(39). Wang M; Vicente MGH; Mason D; Bobadova-Parvanova P Stability of a Series of BODIPYs in Acidic Conditions: An Experimental and Computational Study into the Role of the Substituents at Boron. ACS Omega 2018, 3, 5502-5510. [PubMed: 29876538] 
(40). Jensen TJ; Vicente MGH; Luguya R; Norton J; Fronczek FR; Smith KM Effect of Overall Charge and Charge Distribution on Cellular Uptake, Distribution and Phototoxicity of Cationic Porphyrins in HEp2 Cells. J. Photochem. Photobiol., B 2010, 100, 100-111. [PubMed: 20558079]

(41). Harriman A; Mallon LJ; Ulrich G; Ziessel R Rapid Intersystem Crossing in Closely-Spaced but Orthogonal Molecular Dyads. ChemPhysChem 2007, 8, 1207-1214. [PubMed: 17492823]

(42). Ulrich G; Ziessel R Convenient and Efficient Synthesis of Functionalized Oligopyridine Ligands Bearing Accessory Pyrromethene-BF2 Fluorophores. J. Org. Chem 2004, 69, 2070-2083. [PubMed: 15058955]

(43). Kolemen S; Işik M; Kim GM; Kim D; Geng H; Buyuktemiz M; Karatas T; Zhang XF; Dede Y; Yoon J; et al. Intracellular Modulation of Excited-State Dynamics in a Chromophore Dyad: Differential Enhancement of Photocytotoxicity Targeting Cancer Cells. Angew. Chem. Int. Ed 2015, 54, 5340-5344.

(44). Bartelmess J; Weare WW Preparation and Characterization of Multi-Cationic BODIPYs and Their Synthetically Versatile Precursors. Dyes Pigm 2013, 97, 1-8.

(45). Bartelmess J; Francis AJ; El Roz KA; Castellano FN; Weare WW; Sommer RD Light-Driven Hydrogen Evolution by BODIPY-Sensitized Cobaloxime Catalysts. Inorg. Chem 2014, 53, 45274534. [PubMed: 24725061]

(46). Caruso E; Banfi S; Barbieri P; Leva B; Orlandi VT Synthesis and Antibacterial Activity of Novel Cationic BODIPY Photosensitizers. J. Photochem. Photobiol., B 2012, 114, 44-51. [PubMed: 22682365]

(47). Frath D; Yarnell JE; Ulrich G; Castellano FN; Ziessel R Ultrafast Photoinduced Electron Transfer in Viologen-Linked BODIPY Dyes. ChemPhysChem 2013, 14, 3348-3354. [PubMed: 23946241]

(48). Sunahara H; Urano Y; Kojima H; Nagano T Design and Synthesis of a Library of BODIPY-Based Environmental Polarity Sensors Utilizing Photoinduced Electron-Transfer-Controlled Fluorescence on/off Switching. J. Am. Chem. Soc 2007, 129, 5597-5604. [PubMed: 17425310]

(49). Lu H; Zhang S; Liu H; Wang Y; Shen Z; Liu C; You X Experimentation and Theoretic Calculation of a BODIPY Sensor Based on Photoinduced Electron Transfer for Ions Detection. J. Phys. Chem. A 2009, 113, 14081-14086. [PubMed: 19950967]

(50). Ueno T; Urano Y; Kojima H; Nagano T Mechanism-Based Molecular Design of Highly Selective Fluorescence Probes for Nitrative Stress. J. Am. Chem. Soc 2006, 128, 10640-10641. [PubMed: 16910633]

(51). Komatsu T; Oushiki D; Takeda A; Miyamura M; Ueno T; Terai T; Hanaoka K; Urano Y; Mineno T; Nagano T Rational Design of Boron Dipyrromethene (BODIPY)-Based PhotobleachingResistant Fluorophores Applicable to a Protein Dynamics Study. Chem. Commun 2011, 47, 10055-10057.

(52). Valiev M; Bylaska EJ; Govind N; Kowalski K; Straatsma TP; Van Dam HJJ; Wang D; Nieplocha J; Apra E; Windus TL; et al. Nwchem: A Comprehensive and Scalable Open-Source Solution for Large Scale Molecular Simulations. Comput. Phys. Commun 2010, 181, 1477-1489.

(53). Becke AD Density-Functional Thermochemistry. Iii. The Role of Exact Exchange. J. Chem. Phys 1993, 98, 5648-5652.

(54). Lee C; Yang W; Parr RG Development of the Colle-Salvetti Correlation-Energy Formula into a Functional of the Electron Density. Phys. Rev. B: Condens. Matter Mater. Phys 1988, 37, 785789.

(55). Zhan C-G; Nichols JA; Dixon DA Ionization Potential, Electron Affinity, Electronegativity, Hardness, and Electron Excitation Energy: Molecular Properties from Density Functional Theory Orbital Energies. J. Phys. Chem. A 2003, 107, 4184-4195.

(56). Yanai T; Tew DP; Handy NC A New Hybrid Exchange-Correlation Functional Using the Coulomb-Attenuating Method (Cam-B3lyp). Chem. Phys. Lett 2004, 393, 51-57.

(57). Williams ATR; Winfield SA; Miller JN Relative Fluorescence Quantum Yields Using a Computer-Controlled Luminescence Spectrometer. Analyst 1983, 108, 1067-1071.

(58). Olmsted J Calorimetric Determinations of Absolute Fluorescence Quantum Yields. J. Phys. Chem 1979, 83, 2581-2584. 
(59). Bartelmess J; Weare WW; Latortue N; Duong C; Jones DS Meso-Pyridyl BODIPYs with Tunable Chemical, Optical and Electrochemical Properties. New J. Chem 2013, 37, 2663-2668.

(60). Bañuelos J; López Arbeloa F; Arbeloa T; Salleres S; Amat-Guerri F; Liras M; López Arbeloa I Photophysical Study of New Versatile Multichromophoric Diads and Triads with BODIPY and Polyphenylene Groups. J. Phys. Chem. A 2008, 112, 10816-10822. [PubMed: 18834090]

(61). McCarroll ME; Shi Y; Harris S; Puli S; Kimaru I; Xu R; Wang L; Dyer DJ Computational Prediction and Experimental Evaluation of a Photoinduced Electron-Transfer Sensor. J. Phys. Chem. B 2006, 110, 22991-22994. [PubMed: 17107134]

(62). Kennedy DP; Kormos CM; Burdette SC Ferribright: A Rationally Designed Fluorescent Probe for Redox Active Metals. J. Am. Chem. Soc 2009, 131, 8578-8586. [PubMed: 19459701]

(63). Lu H; Mack J; Yang Y; Shen Z Structural Modification Strategies for the Rational Design of Red/Nir Region BODIPYs. Chem. Soc. Rev 2014, 43, 4778-4823. [PubMed: 24733589]

(64). Karlsson JKG; Harriman A Origin of the Red-Shifted Optical Spectra Recorded for AzaBODIPY Dyes. J. Phys. Chem. A 2016, 120, 2537-2546. [PubMed: 27046505]

(65). Nithya R; Kolandaivel P; Senthilkumar K Understanding the Absorption and Emission Spectra of Borondipyrromethene Dye and Its Substituted Analogues. Mol. Phys 2012, 110, 445-456.

(66). Grä K; Korzdorfer T; Kummel S; Thelakkat M Synthesis of Donor-Substituted Meso-Phenyl and Meso-Ethynylphenyl BODIPYs with Broad Absorption. New J. Chem 2013, 37, 1417-1426.

(67). Zhao N; Xuan S; Fronczek FR; Smith KM; Vicente MGH Stepwise Polychlorination of 8Chloro-BO DIPY and Regioselective Functionalization of 2,3,5,6,8-Pentachloro-BODIPY. J. Org. Chem 2015, 80, 8377-8383. [PubMed: 26186141]

(68). Katsumi N Synthesis, Luminescence Quantum Yields, and Lifetimes of Trischelated Ruthenium(Ii) Mixed-Ligand Complexes Including 3,3'-Dimethyl-2,2' -Bipyridyl. Bull. Chem. Soc. Jpn 1982, 55, 2697-2705.

(69). Dhokale B; Jadhav T; Mobin SM; Misra R Meso Alkynylated Tetraphenylethylene (Tpe) and 2,3,3-Triphenylacrylonitrile (Tpan) Substituted BODIPYs. J. Org. Chem 2015, 80, 8018-8025. [PubMed: 26191612] 
<smiles></smiles>

$1 \mathrm{~A}$<smiles></smiles>

5A<smiles></smiles>

$2 A$<smiles></smiles>

$6 \mathrm{~A}$<smiles></smiles>

$3 \mathrm{~A}$<smiles></smiles>

$7 A$<smiles></smiles>

4A<smiles></smiles>

9A<smiles></smiles>

10A

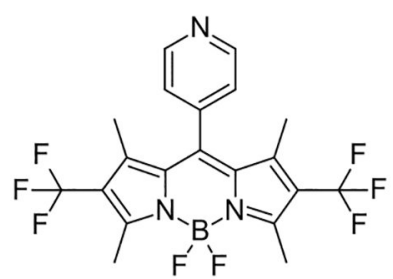

11A<smiles></smiles>

$8 A$

Figure 1.

Structures of the BODIPYs series A used in the calculations. The corresponding $N$ methylated BODIPY cations are denoted "cat". 
<smiles></smiles>

$1 \mathrm{~A}$<smiles></smiles>

1B<smiles></smiles>

$1 \mathrm{C}$<smiles></smiles>

12A

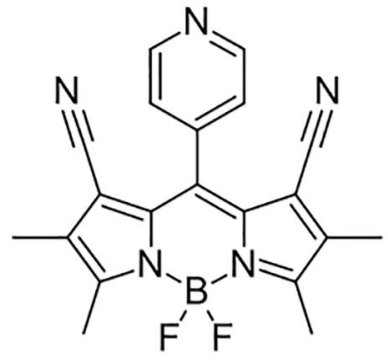

13A<smiles></smiles>

12B

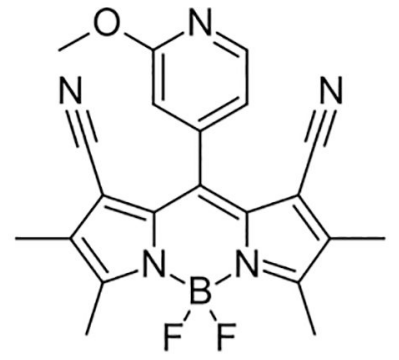

13B<smiles></smiles>

$12 \mathrm{C}$

Figure 2.

Structures of the Py'-BODIPY series A-C used in quantum calculations. 
(a)

(c)
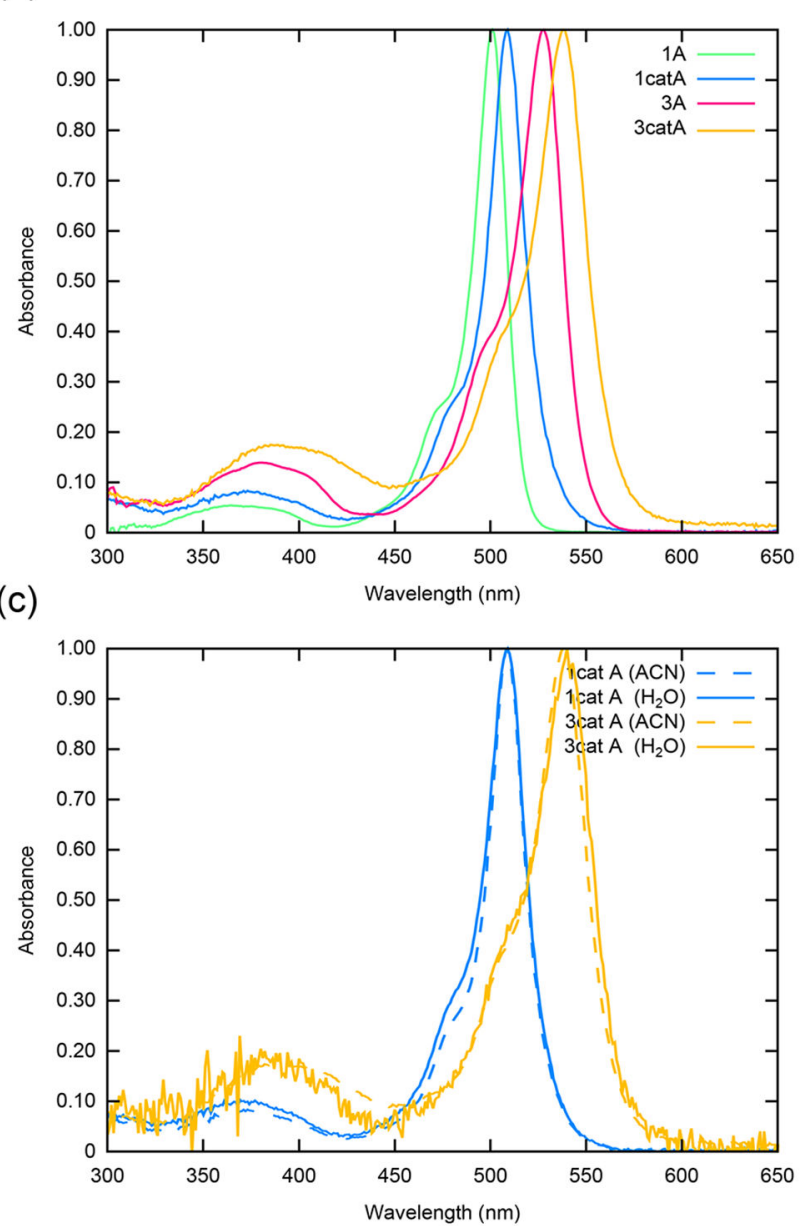

(b)

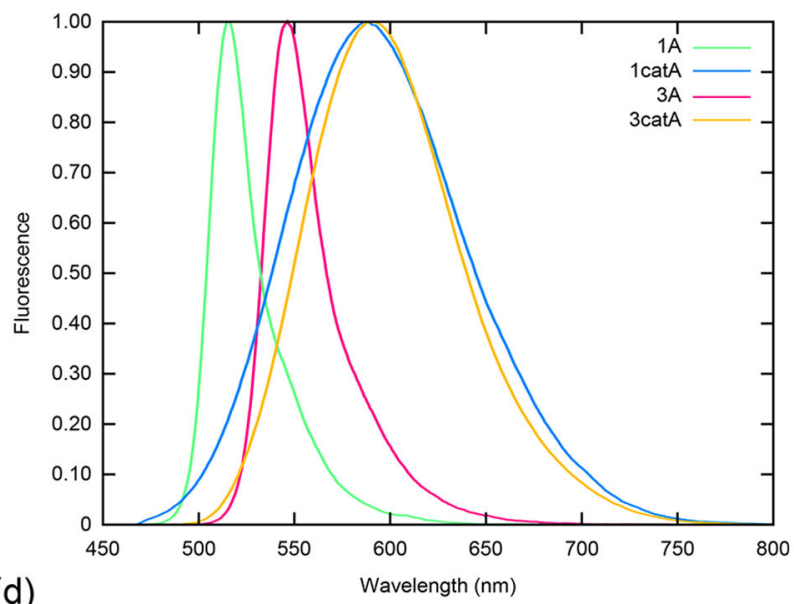

(d)

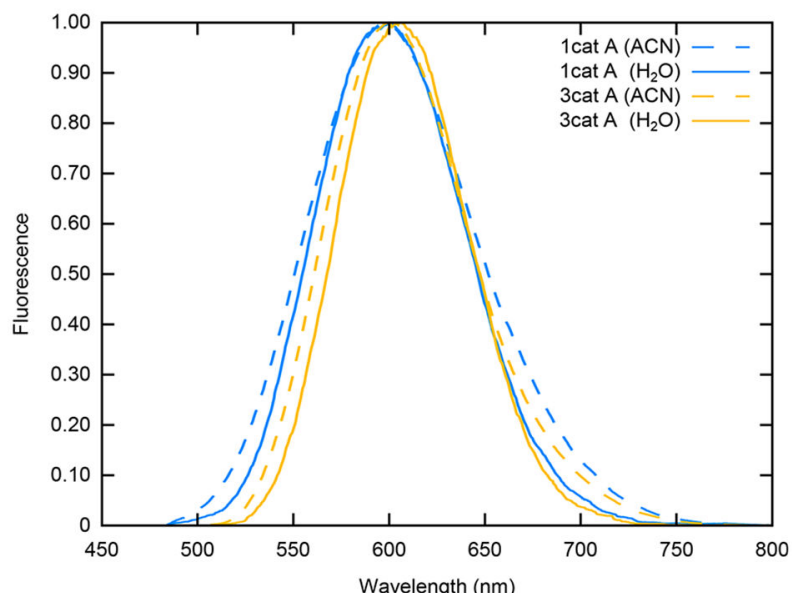

Figure 3.

Normalized (a) absorption and (b) emission spectra of 1A (green), 1catA (blue), 3A (red), and 3catA (yellow) in acetonitrile along with the normalized (c) absorption and (d) emission spectra of 1catA (blue) and 3catA (yellow) in acetonitrile (dashed) and water (solid) at room temperature. 
Table 1.

Calculated Orbital Energies and Vertical Ionization Potentials (eV) for Neutral BODIPYs

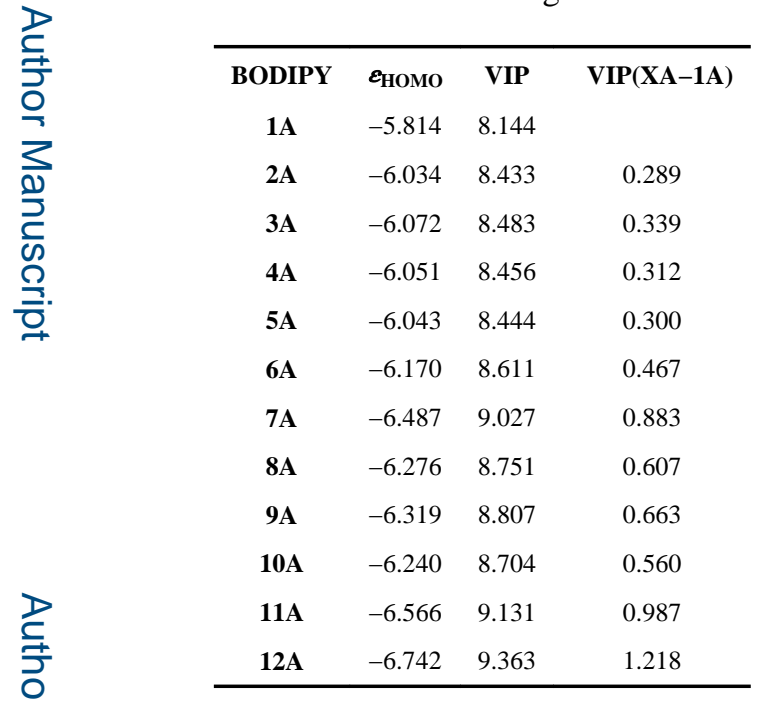




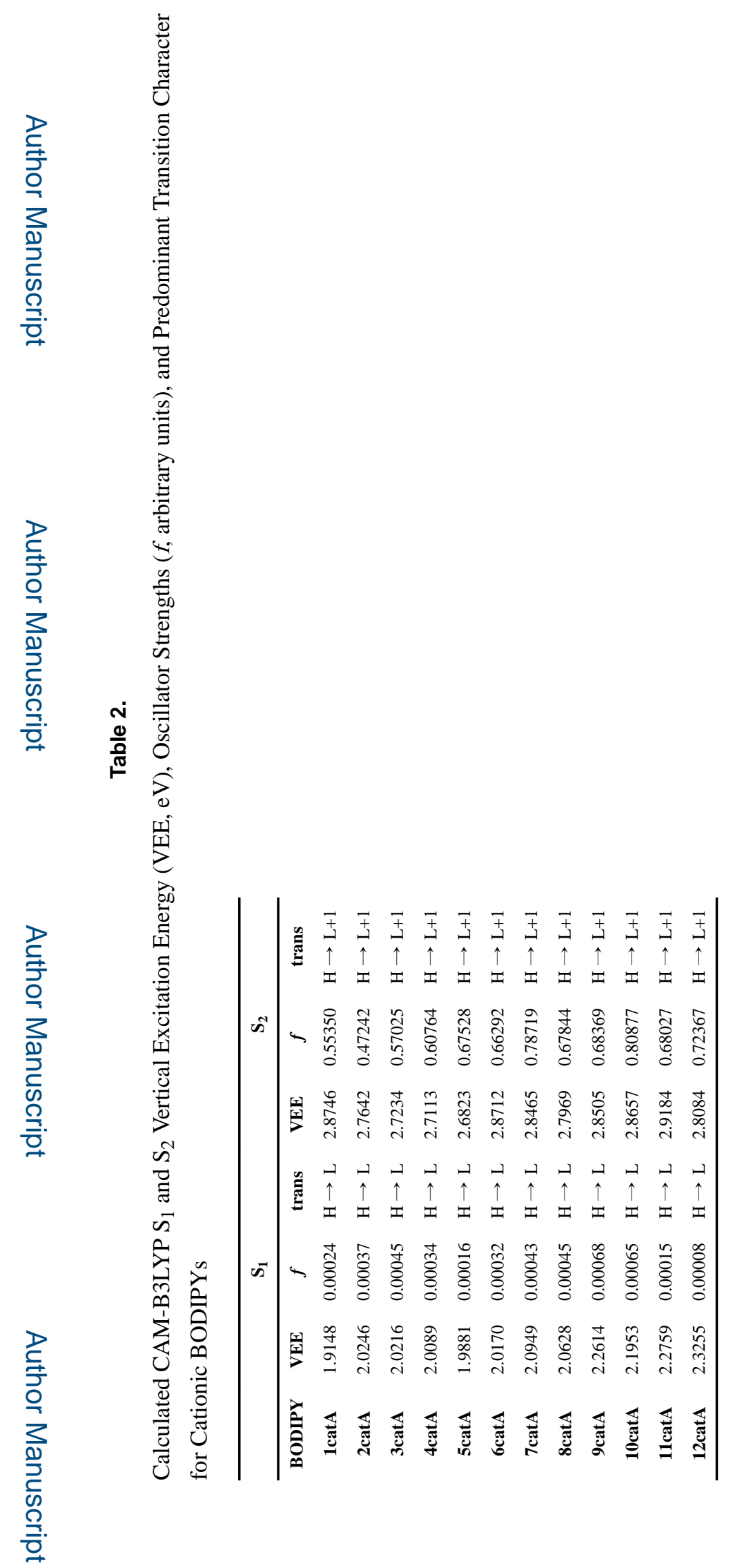

J Phys Chem A. Author manuscript; available in PMC 2019 August 14. 
Table 3.

Calculated Neutral Py'-BODIPY Orbital Energies and Vertical Ionization Potentials (eV)

\begin{tabular}{|c|c|c|c|}
\hline BODIPY & $\varepsilon_{\text {НОМо }}$ & VIP & $\Delta V I P(X-1 A)$ \\
\hline $1 \mathrm{~A}$ & -5.814 & 8.144 & \\
\hline $1 B$ & -5.795 & 8.119 & -0.025 \\
\hline $1 \mathrm{C}$ & -5.775 & 8.094 & -0.050 \\
\hline $12 \mathrm{~A}$ & -6.742 & 9.363 & 1.218 \\
\hline 12B & -6.719 & 9.333 & 1.188 \\
\hline $12 \mathrm{C}$ & -6.693 & 9.298 & 1.154 \\
\hline $13 \mathrm{~A}$ & -6.569 & 9.135 & 0.991 \\
\hline 13B & -6.525 & 9.078 & 0.934 \\
\hline $13 \mathrm{C}$ & -6.380 & 8.888 & 0.743 \\
\hline
\end{tabular}



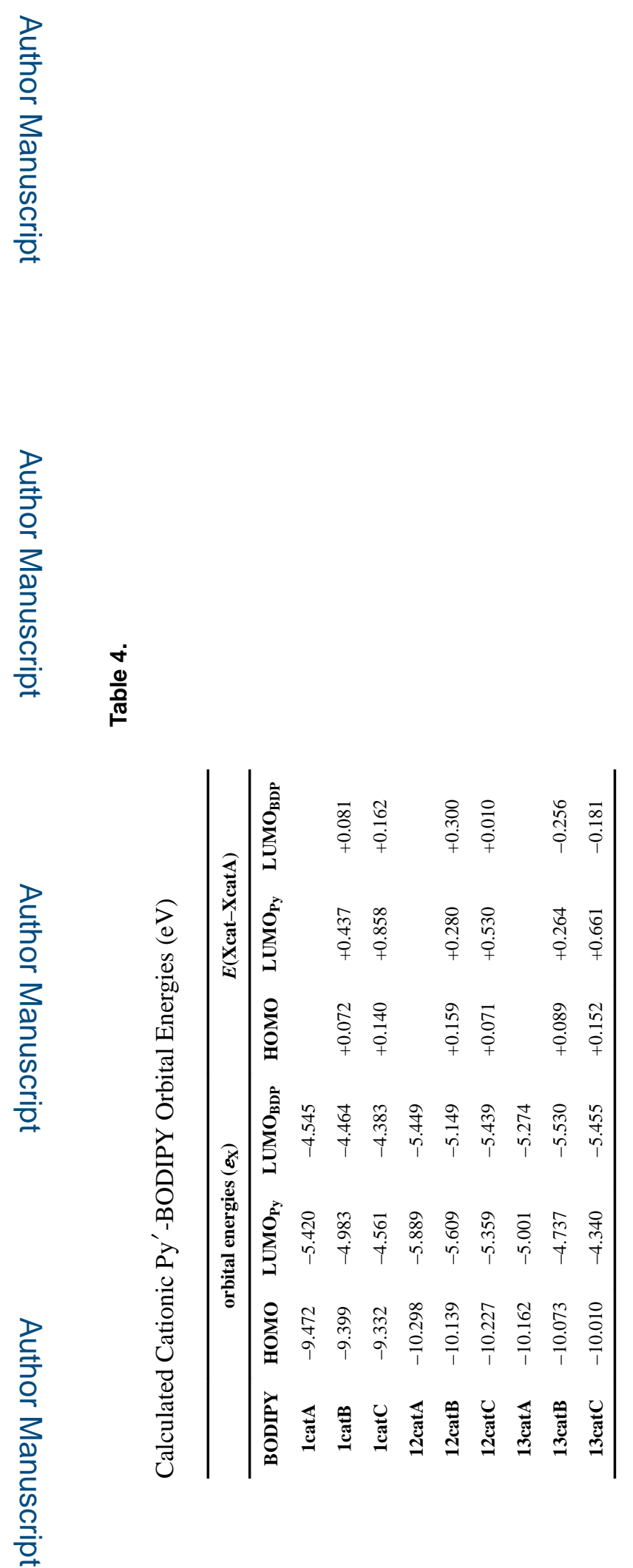

J Phys Chem A. Author manuscript; available in PMC 2019 August 14. 
Table 5.

Calculated $S_{1}$ and Analogous Triplet State Excitations for $S_{1}$ Relaxed Structures of BODIPYs 1 catA and 12 catA

\begin{tabular}{cccccc}
\hline BODIPY & excitation & VEE $(\mathbf{e V})$ & trans & population & $\Delta\left(\mathbf{S}_{\mathbf{1}}-\mathbf{T}_{\mathbf{2}}\right)(\mathbf{e V})$ \\
1catA & $\mathrm{S}_{1}$ & 1.4688 & $\mathrm{H} \rightarrow \mathrm{L}$ & 0.984261 & 0.0319 \\
& $\mathrm{~T}_{2}$ & 1.4369 & $\mathrm{H} \rightarrow \mathrm{L}$ & 0.980000 & \\
\multirow{2}{*}{ 12catA } & $\mathrm{S}_{1}$ & 1.8740 & $\mathrm{H} \rightarrow \mathrm{L}$ & 0.974631 & 0.0319 \\
& $\mathrm{~T}_{2}$ & 1.8421 & $\mathrm{H} \rightarrow \mathrm{L}$ & 0.973013 & \\
\hline
\end{tabular}


Table 6.

Photophysical Properties of Synthesized BODIPYs in $\mathrm{CH}_{3} \mathrm{CN}$ and $\mathrm{H}_{2} \mathrm{O}$

\begin{tabular}{|c|c|c|c|c|c|c|}
\hline \multirow[b]{2}{*}{ solvent } & \multirow[b]{2}{*}{ BODIPY } & \multicolumn{2}{|c|}{$\lambda_{\max }(\mathbf{n m})$} & \multirow[b]{2}{*}{ Stokes Shift (nm) } & \multirow[b]{2}{*}{$\Phi_{\mathrm{f}}$} & \multirow[b]{2}{*}{$\varepsilon\left(\mathbf{M}^{-1} \mathrm{~cm}^{-1}\right)$} \\
\hline & & abs & em & & & \\
\hline \multirow[t]{4}{*}{$\mathrm{CH}_{3} \mathrm{CN}$} & $1 \mathrm{~A}$ & 501 & 515 & 14 & $0.31^{a}$ & 72100 \\
\hline & 1 catA & 509 & 596 & 87 & $0.019^{b}$ & 26000 \\
\hline & $3 \mathrm{~A}$ & 528 & 546 & 18 & $0.58^{a}$ & 50800 \\
\hline & 3 catA & 538 & 600 & 62 & $0.048^{b}$ & 23400 \\
\hline \multirow[t]{2}{*}{$\mathrm{H}_{2} \mathrm{O}$} & 1catA & 509 & 600 & 91 & $0.004^{b}$ & 31600 \\
\hline & 3 cat $\mathrm{A}$ & 540 & 605 & 65 & $0.038^{b}$ & 4100 \\
\hline
\end{tabular}

